\title{
"Voice of Children": Qualitative analysis of children's interpretations regarding nutritional behaviour
}

\author{
Eliška Štefanová1,*, Tibor Baška ${ }^{1}$, Zuzana Boberová2 ${ }^{2}$ Daniela Husárová ${ }^{3}$, Zuzana Dankulincová \\ Veselská $^{3}$, and Henrieta Hudečková ${ }^{1}$
}

${ }^{1}$ Jessenius Faculty of Medicine in Martin, Comenius University in Bratislava, Martin, Slovakia; ${ }^{2}$ Faculty of Science, Pavol Jozef Šafárik University in Košice, Košice, Slovakia; and ${ }^{3}$ Faculty of Medicine, Pavol Jozef Šafárik University in Košice, Košice, Slovakia

Copyright: (C) 2018 E. Štefanová et al. This is an open access article licensed under the Creative Commons Attribution License (http://creativecommons.org/licenses/by/4.0/).

\begin{abstract}
Background: Understanding opinions, attitudes and knowledge of schoolchildren regarding eating habits is essential to develop effective preventive measures in this target group. Objective: The aim of the study was to find opinions and attitudes of schoolchildren regarding nutrition and related behaviour. Methods: Data were collected in selected elementary schools from April to June 2015. Pupils of 5th ( 7 girls, 7 boys), 7 th ( 4 girls, 4 boys) and 9th ( 8 girls, 10 boys) grades debated their opinions and attitudes regarding eating habits during sessions in classrooms and recorded them into worksheets. Qualitative content analysis of the obtained data was performed. Results: Pupils expressed adequate knowledge on healthy eating habits. Attractiveness of sweets is much stronger in comparison to fruits and vegetables. 11 years olds complained about absence of their parents during family mealtime. The main reasons for drinking soft and energy drinks included taste and social motives. Girls were concerned about their body image and mentioned vomiting as a method to reduce body weight. Conclusions: Children possess general principles of healthy eating habits, but they do not implement them in their life. Prevention in nutrition to avoid social-health problems related to unhealthy diet, particularly obesity, should be focused both on children and their parents as role models in development of eating habits.
\end{abstract}

Keywords: nutrition, schoolchildren, health behaviour, participatory approach, qualitative study

\section{Introduction}

Eating habits rank among the most important health determinants (World Health Organization, 2006). Development of healthy eating habits in childhood and their maintenance in adolescence significantly contributes to prevention of several chronic diseases (Babinská et al., 2008). Qualitative and quantitative food content is important regarding energy needs, growth and regeneration requirements (Demory-Luce \& Motil, 2014; Hawkes et al., 2015). In population of developed countries there are several problems regarding eating habits and they are contributing to the development of obesity, other metabolic disorders as well as numerous chronic diseases (Alberti, Zimmet, \& Shaw,

\footnotetext{
* Address for correspondence: Eliška Štefanová, Department of Public Health, Jessenius Faculty of Medicine in Martin, Comenius University in Bratislava, Malá Hora 11149/4B, 03601 Martin, Slovakia. E-mail: eliska.stefanova@gmail.com
}

2006; Babjaková \& Sekretár, 2015). Skipping breakfast is associated with unhealthy eating habits and is connected with overweight and obesity during adulthood (Holubčíková, 2016; Keski-Rahkonen, Kaprio, Rissanen, Virkkunen, \& Rose, 2003). Regular consumption of soft drinks increases energy intake and leads to increased risk of obesity and tooth decay (Hayden et al., 2013). Insufficient consumption of fruits and vegetables, as an important source of fibres, antioxidants, vitamins and minerals, is a frequent problem (Holubčíková, 2016). Recently, the consumption of energy drinks has become important because of negative effects on health, particularly on the cardiovascular and nervous systems (Ali, Rehman, Babayan, Stapleton, \& Joshi, 2015; Bašková, Baška, \& Holubčíková, 2016). Although health consequences of the abovementioned unhealthy eating habits emerge mostly during adulthood, their roots extend into childhood. Unhealthy eating habits can be caused at least partially by a knowledge deficit in this area (Naaeni et al., 2014). 
Other significantly contributing causes include efforts of independence, peer pressure, increased mobility without parental supervision as well as spending more time in school (Demory-Luce \& Motil, 2014). Concerns regarding body image not corresponding with an objective reality and leading to inappropriate ways of weight control are specific problem regarding nutrition (Wilson, Tripp, \& Boland, 2005). Better understanding of factors determining children's lifestyle is one of the keys to effective prevention of chronic diseases associated with unhealthy eating habits.

Health Behaviour in School-Aged Children (HBSC) study provides representative epidemiological data on eating habits in 11-, 13-, and 15-year-old adolescents. In the survey carried out in 2013/2014 in Slovakia, as much as $60 \%$ of 15 -year-old girls reported breakfast skipping during the week (Bašková \& Holubčíková, 2015). Only one in ten respondents reported eating breakfast together with parents. Fruit consumption on daily basis was found in $23 \%$ of 15 -year-old boys and daily vegetable consumption was reported among one third of girls. Consumption of sweets slightly decreased in 15-year-old boys between 2009/2010 and $2013 / 2014$ - from $41 \%$ to $31 \%$. One third of 15 -yearold boys reported daily consumption of soft drinks. Although consumption of soft drinks declined between $2009 / 2010$ and 2013/2014, consumption of energy drinks increased during the same time. $35 \%$ of 15 -yearold boys mentioned consumption of energy drinks. Inadequate body image is mostly a problem of girls. More than one third of 13- and 15-year-old girls considered themselves as obese, although overweight and obesity was present only in less than one in ten girls (Bašková \& Holubčíková, 2015; Madarasová Gecková, Veselská, \& Kollárová, 2011).

Information on views of schoolchildren is important to understand subjective aspects of the issue as a basis for further analysis. Some findings suggest that planning strategies and action plans as a part of national policy planning for health promotion may not be in accordance with children's ideas about health (Spencer, 2013) because in this context they hold the position of silent voices in society (Fattore, Mason, \& Watson, 2007). In order to develop effective health promotion interventions, it is crucial to deepen the knowledge of how children understand their health in the context of everyday life and to create a space for their genuine participation including consulting with children on issues that affect them. Such research is usually based on interactive participatory methods (Fattore et al., 2007; Simovska, 2007; Spencer, 2013). Interactive research methods based on tasks such as drawing, photographing, diaries, worksheets (Crivello, Camfield, \& Woodhead, 2009) are used as visual and written techniques which also enable children to have an easier way of self-expression and help them feel more natural within the research process (Solberg, 1996).

Subjective views significantly influence approach towards prevention and thus compliance with provided interventions. Effective preventive measures should be appropriately tailored to respect specific values and priorities of children of the given target group to positively motivate them for behavioural changes. Keeping this idea, the project "Voice of Children" was realised. The project is a follow-up of the HBSC survey carried out in 2013/2014 in Slovakia. Qualitative subjective data from 11-, 13- and 15-year-old children in respective areas of health-related behaviours were collected (Boberová et al., 2016).

The aim of the project was to provide insight into children's views regarding the most critical areas of health behaviour using qualitative analysis. This paper deals with one of them - nutritional behaviour, i.e., eating habits and health, family mealtime, soft and energy drinks as well as body image. Findings can help as a starting point for further analysis as well as development of effective preventive measures in nutrition in the future.

\section{Methods}

Design of the study was based on a qualitative approach. Data were collected in classrooms of selected elementary schools during discussion sessions (Boberová et al., 2016). The target population was represented by HBSC study population (11-, 13- and 15-year-old schoolchildren). The sample inclusion criteria were: (1) the schools represented typical schools from different regions in Slovakia, (2) the schools represented urban and rural regions. Based on inclusion criteria and topic-oriented meetings, two elementary schools were selected. To include all age groups, three classes of different grades were selected. As the result of this sampling procedure, the final sample was represented by children attending 5 th grade ( 7 girls, 7 boys, modal age of 10-11 years), 7 th grade ( 4 girls, 4 boys, modal age of 12-13 years) and 9th grade ( 8 girls, 10 boys, modal age of 14-15 years). The ratio of boys and girls was about the same in all age groups. Informed consent was signed by 44 parents. From this group, 40 pupils (90.9\% response rate) participated in the study. Meetings were carried out from April to June 2015. We met with each group of children tree times in a period of three weeks. The aim of the first meeting was to acclimatise the pupils to the participatory technique used in our approach and the following two meetings were 
devoted to two different themes. This paper deals with theme of nutritional behaviour.

Worksheets with open questions were used to collect the data to be analysed. Each child obtained one worksheet containing eight pages with special designated places to write down his/her ideas (Boberová et al., 2016). The initial page included a picture and boxes to fill in date and gender. The following pages were divided in several parts by topics (eating habits, family mealtime, soft and energy drinks, body image). The page about eating habits was divided to three sections: (1) comments by respondent himself/herself, (2) different comments in group, (3) final group opinion. After an initial discussion, children wrote down their views regarding the presented topic into blanks of a worksheet. The rest of the worksheets (another four pages) were divided into sections with questions to express ideas regarding data of HBSC study 2013/2014 presented in a PowerPoint presentation (Boberová et al., 2016). Group interactions helped children explore and resolve other perspectives and make them create their own individual view on the topic (Tong, Sainsbury, \& Craig, 2007). Working group in the classroom consisted from moderator and observer (Švaříček et al., 2007). Meetings with children were guided by trained and experienced researchers in the position of moderator during regular class time. The moderator held discussions with children. Discussions were spontaneous, without a predefined scenario. Asked questions were mostly open and the moderator just kept the discussion within the topic. Basically, children were asked to say what was on their mind when they hear four topics on which we focused. The role of the observer was to write down verbal statements of pupils to be analysed (Kidd \& Parshall, 2000).

The principle of the worksheet was based on:

- verbalisation of the key meanings for schoolchildren in respective areas,

- comparison of own meanings with peers in the working groups,

- and formulation of recommendations for future research of the presented areas.

Worksheets were used as the main source for analysis, but also data collected by the observer. All collected data were processed using directed qualitative content analysis (Boberová et al., 2016). The analysis began by reading through worksheets to highlight all parts of text in relation to aims of the study and respective areas (Hsieh \& Shannon 2005). Second, meaning-carrying units which correspond with the aim and respective areas were extracted and then coded. To identify similarities and dissimilarities, the codes were compared, sorted and abstracted into subcategories and final thematic categories. The analysis conducted three authors of the study to increase trustworthiness of the study.

In this paper, we analyse collected data on nutrition with special focus on:

- eating habits and health,

- family mealtime,

- soft and energy drinks,

- body image.

The study was approved by the Ethics Committee of the Faculty of Medicine, Pavol Jozef Šafárik University in Košice. Informed consents were distributed to the schools and through schoolmasters sent to parents for signature beforehand. Parents, who agreed with participation of children in our project, sent the signed informed consent back to class teacher.

\section{Results}

Results based on children's responses are classified into specific areas important for the issue.

\section{Eating habits and health}

Regarding relationship between eating habits and health, 11-year-old children possess basic information regarding which foods are healthy and which are unhealthy. Children of all age groups consider fruits and vegetables as healthy, and tasty. They also recommend consuming meat, breads and pasta and to drink water first of all. Opinions change with increasing age as children gain more experience and develop their own view on nutrition.

"Fruits and vegetables are healthy." (11 years old)

"It is necessary to eat healthy, to consume fruit and vegetables, but also meat." (15 years old)

They often consider energy drinks as unhealthy, but also mention pizza, fries, chips and other fast food meals. Foods to be avoided are soft drinks and fatty foods. Negative attitude towards soft drinks is expressed in 13- and 15-year-old groups. Older pupils also recommend avoiding consumption of sweets and fast foods as well as drinking of coffee and alcohol.

"Unhealthy are meals like fries, chips and sweets."

(11 years old)

"You should not drink coffee, soft drinks and McDonald fast food." (13 years old)

According to children, healthy foods positively influence the mind and they consider regularity of meals important. There is an opinion that skipping of breakfast, lunch or dinner is unhealthy. As an optimal meal frequency, they report 5 meals a day, including snacks. Knowledge regarding a relationship between 
lifestyle and health and effects of eating habits on lifespan are presented among older children.

"It is not healthy to skip breakfast because our organism doesn't start without it." (11 years old)

"Eating regularly is better than eating once a day. Very important is to pay attention what we eat." (15 years old)

"If we eat better, it results in a healthy person." (15 years old)

Emphasis is given on time of eating, too. Various attitudes are expressed: some children think that people should not eat after 6 p.m. and some of them consider eating after this time as appropriate. Some of them think that they cannot gain weight from healthy foods or that eating healthy results in good health. They think that healthy food contains vitamins needed for body.

Children report that unhealthy eating habits lead to a shortened life. Consumption of unhealthy foods results in bad health. They expressed many opinions, e.g., that coke is bad for children's teeth, chocolate makes people fat and drinking of coffee increases blood pressure.

\section{Family mealtime}

Family mealtime plays significant role in children's lives. They perceive family as a social support in their nutrition. They believe that spending time together eating can help them to practice principles of social etiquette. There is an opinion among children that family mealtimes help to strengthen healthy eating habits. According to the children, family mealtimes have an influence on children's mental health and thus children's health depends on their parents.

"Parents usually don't have time for their kids due to the work and therefore a lot of children don't know how to use principles of social etiquette related to eating in society." (11 years old)

"During family mealtime we have opportunity to talk about how our day was and what we did." (13 years old)

"When we have lunch or dinner once in a while as a family, the food is definitely tastier and healthier than food which I have to prepare sometimes by myself in a hurry." (15 years old)

"I eat healthier during family mealtimes." (15 years old)

Some of the children who do not want to spend family mealtimes or do not have opportunity to eat together are concerned that their children in the future will not have time and interest to eat together.

Younger age groups of children consider family mealtime as important. Children perceive absence of family meals as a parental fault. With increasing age, the opinion changes and older children try to rationalize absence of family mealtimes.
"Parents are unable to find time for their children." (11 years old)

"Most of the children have breakfast or lunch in front of computers or television." (13 years old)

"Absence of family mealtime is not bad. Communication and maintaining of relationship with parents are possible during the entire day, not only during eating together." (15 years old)

In general, children present negative attitude towards absence of family mealtime. They think that it is better to eat together as a family and they consider the inability of parents to find time to eat together as inappropriate. However, some of them report feeling better and more comfortable when eating alone as an opportunity to avoid family confrontations. Another opinion expresses that if the family does not eat together, children are not forced to eat what is cooked and therefore they can eat what is tasty for them (15 years).

Children reported work of the parents as the most common reason for absence of family mealtime. This opinion is expressed in all age groups, although older pupils better understand it.

"Parents have a lot work to do, so I would rather let them relax when they arrive home and make dinner by myself." (15 years old)

Another mentioned problem includes inability to find time to be together, even when all family members are at home. Children prefer to eat in front of the television rather than with parents or they like to spend time with friends outside and instead of family mealtime they prefer fast food.

"Children rather eat in McDonalds than at home with family." (15 years old)

Younger children tend to look for solving their answers and suggest some ways to decrease absence of family mealtimes.

"It would be perfect if there would be a possibility to shorten parents' working time or if they are able to take 2-hours break during a lunch to have family mealtime." (11 years old)

"Parents should wake up us in the morning and hurry up home after work to get family mealtime." (11 years old)

\section{Soft and energy drinks}

Consumption of soft and energy drinks is familiar for children; however, they report occasional use, mainly as a part of special events as birthday celebration etc.

"I drink soft drinks only during celebrations or when

hiking, to boost organism with energy." (13 years old)

Drinking of energy drinks is considered as cool between youngsters. Boys report that they tend to drink 
them because of energy intake. As boys get older, the energy drinks become a part of their life.

"If we could sleep more, we would not have to drink energy drinks, because we would have enough energy." (15 years old)

All age groups express the opinion that these drinks are unhealthy. The attitudes of 11-year-old children are rather neutral. They know that these drinks are unhealthy but they think at the same time that their consumption will not kill them so they do not care about other consequences related to soft and energy drinks. 15-year-old children possess more complex opinions about the consumption of soft and energy drinks and are aware of the health consequences.

"Children who drink them are more likely to have

headaches and other health problems." (15 years old)

According to children, soft and energy drinks may cause various cardiovascular problems and may lead to increased blood cholesterol level or glycaemia, obesity or diabetes. As other negative impacts on health, they mention tooth decay, headache, hyperactivity, insomnia or heart attack. They consider children healthier if they do not drink these types of drinks. Regarding ingredients used in soft and energy drinks and their effect on human body, children are informed about it. Children know, that energy drinks consumption makes going to sleep difficult in the evening and increases risk of oversleeping in the morning.

"Drinking of energy drinks may cause heart problems." (11 years old)

"Children who drink them will have heart problems because of caffeine and taurine presence." (15 years old)

Children share an opinion that these drinks should not be sold to adolescents under 15 or 18 years old. They suggest considering soft drinks, a 10 years age limit. Recommendations given by children to decrease the consumption can be divided into four groups:

1. Banning beverages - the consumption of soft drinks should be banned in schools, same as the consumption of energy drinks is.

2. Restriction of sales - a lot of children consider age limitations of soft and energy drinks important, similar to alcohol beverages.

3. Parental supervision - children believe that parental supervision is one of most important preventive measures and they also think that parents should appropriately explain why drinking of these drinks should be restricted.

"Parents should not give children money or when they do, they should be able to control what they buy for eating/drinking." (15 years old)

4. Healthy alternatives - children mention mostly water, fruit juice or tea.
"I am used to drinking water since I was little. Water doesn't make you thirsty, doesn't contain artificial colorants and is tasty." (11 years old)

\section{Body image}

Younger children usually have an idea about who they want to be. They can assess the situation without condemnation. In older age, they tend to be more critical of themselves. Their opinion regarding others seems to be more understanding. Boys claim that girls often consider themselves fat, even though it is not true. Only one girl reported dissatisfaction (11 years). Some of them want to gain weight (boy, 11 years), to get taller or stronger (boy, 11 years) etc.

"I'm thin, but I see myself as normal. I try to eat to get taller and stronger. I am satisfied with myself." (11 years old)

"Everybody should look as he/she wants to and how he/she feels fine." (15 years old)

The term "dieting" is familiar in all age categories. All age groups prefer the opinion that it is not healthy for them to be dieting, but particularly 15-year-old children. 11 year olds consider it bad when someone checks their weight all the time. They think that when thin children are dieting, it is not healthy at all. Children also think that girls are dieting mostly because of boys. Girls have lower self-confidence and they want to attract boys, so they choose to starve to be thin. On the other hand, boys prefer exercising.

"It is definitely better to exercise than to stick to diet, when we want to lose weight. Losing weight by dieting may become chronic." (15 years old)

"Girls want to be adored, so they stick to diets, while boys prefer to go to the gym instead." (15 years old)

Regarding appropriate methods of weight loss, the most common opinion in children was to eat well and healthily. They also recommend drinking more water, eat less unhealthy food, eat less sweets and get all of nutrients needed from food for adequate organism growth. According to the children, a good diet means higher consumption of fruits and vegetables and absence of eating sweets. This kind of diet could be suitable for overweight or obese children, they say. Sport, according to children is a second suitable alternative for weight loss. Sport is preferred mostly by 11 -year-old children mainly because most of them are members of some sport club or spend their free time with sport activities like swimming, skiing etc. They reported that an increased number of physical education hours at schools would be taken positively.

"If I gain weight, I will sweat it out with some sport activity in physical education." (11 years old)

"It is better to practise some kind of sport activity then to stick to a diet." (11 years old) 
11-year-old children consider self-induced vomiting and smoking as inappropriate ways to reduce weight. 15-year-old children think that if someone wants to lose weight, it is better to exercise and to reduce consumption of sweets and other unhealthy foods. They also express the thought that children are at age when dieting is not good for a young body under development.

"We are still in the growth phase - we should not stick to diets and we should not eat more than it is necessary." (15 years old)

\section{Discussion}

The findings of our study provide qualitative insight into attitudes and knowledge on eating habits among schoolchildren. Understanding ideas shared among children complement quantitative data obtained in the HBSC survey.

Regarding eating habits, we found that children are aware of the role of fruits and vegetables for health, but they do not mention their opinion about sweets. However, this finding is not in accordance with HBSC results, showing consumption of sweets being significantly higher than consumption of fruits and vegetables (Bašková \& Holubčíková, 2015).

Further, family mealtime presents an important issue of children's interest as they consider absence of family mealtimes as a problem. While younger age groups try to find a way for the presence of a family mealtime, older children seem to be more indifferent to its absence. We consider this kind of attitude positively because of importance of family mealtime for development of social relationships and healthy eating habits. Parents represent a primary source for children to learn how to eat, how to choose food, how to prepare it and how to behave while consuming (Birch, Savage, $\&$ Ventura, 2007). If they have an absence of family mealtimes they have to obtain eating behaviour models by themselves on account of absence of proper eating etiquette (Ramos \& Stein, 2000). Based on multiple scientific researches, family mealtime is related to healthier eating habits and has positive impact not only in children but in all family members, so it is recommended to find time to eat together (Hammons \& Fiese, 2011).

Children do not consider consumption of soft drinks as significant, although it is a widespread problem in Europe (Duffey et al., 2012). As a main reason to drink them, children report taste and peer pressure. The prices of these drinks were not mentioned, however, literature data suggest, it is another factor influencing preference of specific kinds of soft drinks (Block, Gillman, Linakis, \& Goldman,
2013). Inadequate consumption of soft drinks may have negative influence on children's health, such as weight gain, hypertension and other cardiovascular or metabolic problems (metabolic syndrome, type 2 diabetes) (Bremer \& Lustig, 2012). The problem is mostly related to higher intake of energy and carbohydrates and inadequate consumption of fruits, vegetables, fibre and other macronutrients which are important for healthy development of the body (Vartanian, Schwartz, \& Brownell, 2007).

Our results indicate that consequences of consumption of energy drinks are often underestimated, most probably due to their delayed health impact. Sugar and caffeine, present in these drinks, play an important role in development of obesity and type 2 diabetes, however these negative effects usually occur in higher ages, mainly in adulthood (Deliens, Clarys, De Bouordeaudhiuj, \& Deforche, 2015; Schulze et al., 2004).

Girls seem to be more critical about their body image. This finding is in accordance with quantitative HBSC data (Bašková \& Holubčíková, 2015). According to respondents' reports, adequate way to reduce body weight is associated with normal eating, however, we should expect that children are hesitant to confess to unhealthy eating habits such as starving, self-induced vomiting and smoking even despite an anonymous approach. Girls who tend to perfectionism are more likely to practice unhealthy body weight reduction techniques, such as starving, self-induced vomiting, usage of laxatives or diuretics, etc. (Forbush, Heatherton, \& Keel, 2007).

\section{Preventive measures}

As seen in children's reports, family plays an important role in development of their eating habits. So, in preventive measures, attention should be paid to this issue, including education of parents to promote health knowledge, including healthy eating habits of their children (May, Chai, \& Burrows, 2017). Parents should be educated on the importance of family meals and keeping of family relationships, learning on social etiquette and forming of eating habits. In adolescence, meals consumed at home are rare and thus eating with parents is uncommon, as well. Such a situation prevents parents to be role models for eating habits (Benton, 2004). Positive atmosphere in household has a positive impact on children's food consumption. Higher consumption of fruits and vegetables and lower consumption of fats was found in individuals having family mealtimes on a regular basis (Gillman et al., 2000). Children need parents' support to know how to implement knowledge on nutrition learnt in school. Positive changes in eating behaviour persist longer if interventions involve the whole family. Engagement of 
children in meal preparation leads to increased interest in healthy foods (Casey \& Rozin, 1989; World Health Organization, 2006).

School environment plays another significant role in the development of eating habits, since children spend a significant time there and usually eat in school cafeterias (Driessen, Cameron, Thornton, Lai, \& Barnett, 2014). Education on healthy nutrition should be implemented into school education to provide pupils necessary knowledge and skills regarding healthy eating habits (U.S. Department of Health and Human Services, Centers for Disease Control and Prevention, 2013). Besides curricular education, general school environment considerably contributes to the development of attitudes and practice regarding healthy lifestyle (World Health Organization, 2006). Such measures would be positively accepted by children as indicated in their reports. However, we should keep in mind that children grow up in a world full of media influence and advertisements. It is important to educate children about media, to help them critically evaluate information and to detect false techniques, which media use to persuade people. For example, considering body image, the most widespread technique is using Photoshop to make people in magazines look younger, more attractive and slimmer. Such advertisement can negatively influence body image in adolescents, especially girls (Morris \& Katzman, 2003).

Energy drinks represent another prominent issue of potential legislative changes. Lack of regulation resulted to their aggressive advertisement and promotion. Marketing is primarily focused on adolescent boys to promise them a stimulating effect and an increase in energy and strength. So, they come to a false conclusion that if a product is advertised, it is safe to buy it. Therefore, it is important to educate children to make them recognize what is appropriate for their health and lifestyle (Kline, 2005; Pitt, Berger, \& Sheehan, 2016; Reisigg, Strain, \& Griffiths, 2009). An appropriate legislative regulation including age limitation is needed to decrease consumption of these kinds of drinks among children and adolescents.

\section{Limitations}

This study has several limitations. Results are based on a relatively small sample which cannot be considered as representative. However, the reports were qualitatively analysed with the purpose to point out aspects significant for prevention as baselines for formulation of hypotheses of further research in this field. Therefore, we suppose that the above-mentioned limitation does not critically alter the contribution of the study. On the other hand, our study, as one of the first in Central Europe employing a qualitative analysis method in the problem of eating habits in children, can be considered as a pathfinder in this area and a starting point for further research. The qualitative results advantageously supplement existing epidemiologic data and contribute to their proper interpretation.

Working with groups of children can be also considered as a limitation. It is difficult to work in a big group of children when collecting qualitative data because a lot of opinions can be lost in discussion. Another possible limitation includes an uneven number of children in the working groups as well as too large groups (e.g., 9th grade comprised 18 children). Cluster sampling was only partially successful due to logistical reasons.

Our data cover younger as well as older children from an urban area, but only older ones from a rural area, therefore we might be missing specific content for younger children living in rural area. According to HBSC findings in Slovakia some of the aspects of nutritional behaviour show differences across age groups, e.g., decrease of regular breakfasts as well as increase of energy drink consumption with increased age (Bašková \& Holubčíková, 2015). To better understand role of age in development of nutritional behaviour, further research is needed.

\section{Conclusions}

In the end, the results indicate several implications: Although pupils possess basic information on healthy eating, they only partially put their knowledge into practice. Significance of family background and parental approach are remarkably indicated. Attention should be extended also to parents as important role models in development of eating habits of their children. Children are aware of a role of legislative regulations regarding soft and energy drinks and their positive approach towards them can be expected. Girls were more critical about their body image.

\section{Acknowledgments}

The study was partially supported by the Research and Development Support Agency under contract no. APVV 0032-11 and by the Scientific Grant Agency of the Ministry of Education, Science, Research and Sport of the Slovak Republic and the Slovak Academy of Science (reg. no. 1/0981/15).

The authors would like to thank all the members of the Department of Health Psychology, Faculty of Medicine, Pavol Jozef Šafárik University in Košice who collaborated on this project and participated in data collection and analysis. We extend our thanks also to 
all the schoolchildren who participated in this project as well as their teachers who made possible to carry out the project.

\section{Conflict of interest}

There were no conflicts of interest.

\section{References}

Alberti, K. G., Zimmet, P., \& Shaw, J. (2006). Metabolic syndrome - a new world-wide definition. A consensus statement from the International Diabetes Federation. Diabetetic Medicine, 23, 469-480.

Ali, F., Rehman, H., Babayan, Z., Stapleton, D., \& Joshi, D. D. (2015). Energy drinks and their adverse health effects: A systematic review of the current evidence. Postgraduate Medicine, 127, 308-322.

Babinská, K., Vitáriušová, E., Hlavatá, A., Rosinský, J., Babinská, K., Jr., Koštálová, L., ... Kovács, L. (2008). Stravovacie návyky žiakov základných škôl na Slovensku [Eating habits of younger age pupils in relation to their health]. In L. Kovács, K. Babinská, \& L Ševčíková (Eds.), Nové trendy vo výžive detí (pp. 21-31). Bratislava, Slovakia: Comenius University in Bratislava.

Babjaková, J., \& Sekretár, S. (Eds.). (2015). Nutrition and food safety in public health. Bratislava, Slovakia: Comenius University in Bratislava.

Bašková, M., Baška, T., \& Holubčíková, J. (2016). Consumption of sweetened soft drinks and energy drinks in adolescents in Slovakia: Implications for paediatric nursing. Central European Journal of Nursing and Midwifery, 7, 390-395.

Bašková, M., \& Holubčíková, J. (2015). Nutričné správanie [Nutritional behaviour]. In A. Madarasová Gecková \& Z. Dankulicová (Eds.), HBSC - Slovensko 2013/2014: Národná správa o zdraví a so zdravím súvisiacom správaní 11-, 13- a 15-ročných školákov (pp. 38-61). Košice, Slovakia: WHO Country Office in Slovakia.

Benton, D. (2004). Role of parents in the determination of the food preferences of children and the development of obesity. International Journal of Obesity, 28, 858-869.

Birch, L., Savage, J. S., \& Ventura, A. (2007). Influences on the development of children's eating behaviours: From infancy to adolescence. Canadian Journal of Dietetic Practice and Research, 68, 1-56.

Block, J. P., Gillman, M. W., Linakis, S. K., \& Goldman, R. E. (2013). "If it tastes good, I'm drinking it": Qualitative study of beverage consumption among college students. Journal of Adolescent Health, 52, 702-706.

Boberová, Z., Belák, A., Dankulincová Veselská, Z., Husárová, Z., Baška, T., \& Madarasová Gecková, A. (2016). „Chceme počut ich hlas“ - kvalitatívny výskum interpretácií školákov ku kvantitatívnym výskumným zisteniam štúdie HBSC [ "We want to hear their voices" - the qualitative research on the school-children interpretations of the quantitative research findings HBSC study]. Mládež a spoločnost', 22(3), 71-81.
Bremer, A. A., \& Lustig R. H. (2012). Effects of sugar-sweetened beverages on children. Pediatric Annals, 41, 26-30.

Casey, R., \& Rozin, P. (1989). Changing children's food preferences: Parent opinions. Appetite, 12, 171-182.

Crivello, G., Camfield, L., \& Woodhead, M. (2009). How can children tell us about their wellbeing? Exploring the potential of participatory research approaches within young lives. Social Indicators Research, 90, 51-72.

Deliens, T., Clarys, P., De Bourdeaudhuij, I., \& Deforche, B. (2015). Correlates of university students' soft and energy drink consumption according to gender and residency. Nutrients, 7, 6550-6566.

Demory-Luce, D., \& Motil, K. J. (2014). Adolescent eating habits. Retrieved from http://www.uptodate.com/ contents/adolescent-eating-habits

Driessen, C. E., Cameron, A. J., Thornton, L. E., Lai, S. K., \& Barnett, L. M. (2014). Effect of changes to the school food environment on eating behaviours and/or body weight in children: A systematic review. Obesity Reviews, 15, 968-982.

Duffey, K. J., Huybrechts, I., Mouratidou, T., Libuda, L., Kersting, M., DeVriendt, T., ... Popkin, B. M. (2012). Beverage consumption among European adolescents in the HELENA study. European Journal of Clinical Nutrition, 66, 244-252.

Fattore, T., Mason, J., \& Watson, E. (2007). Children's conceptualisation(s) of their well-being. Social Indicators Research, 80, 5-29.

Forbush, K., Heatherton, T. F., \& Keel, P. K. (2007). Relationships between perfectionism and specific disordered eating behaviors. International Journal of Eating Disorders, 40, 37-41.

Gillman, M. W., Rifas-Shiman, S. L., Frazier, A. L., Rockett, H. R., Camargo, C. A., Jr., Field, A. E., ... Colditz, G. A. (2000). Family dinner and diet quality among older children and adolescents. Archives of Family Medicine, 9, 235-240.

Hammons, A. J., \& Fiese, B. H. (2011). Is frequency of shared family meals related to the nutritional health of children and adolescents? Pediatrics, 127, 1565-1574.

Hawkes, C., Smith, T. G., Jewell, J., Wardle, J., Hammond, R. A., Friel, S., ... Kain, J. (2015). Smart food policies for obesity prevention. Lancet, 385, 2410-2421.

Hayden, C., Bowler, J. O., Chambers, S., Freeman, R., Humphris, G., Richards, D., \& Cecil, J. E. (2013). Obesity and dental caries in children: A systematic review and meta-analysis. Community Dentistry and Oral Epidemiology, 41, 289-308.

Holubčíková, J. (2016). Eating habits, body image and health and behavioural problems of adolescents: The role of school and family context (Unpublished doctoral dissertation). Rijksuniversiteit Groningen, Groningen, Netherlands.

Hsieh, H. F., \& Shannon, S. E. (2005). Three approaches to qualitative content analysis. Qualitative Health Research, 15, 1277-1288.

Keski-Rahkonen, A., Kaprio, J., Rissanen, A., Virkkunen, M., \& Rose, R. J. (2003). Breakfast skipping and healthcompromising behaviors in adolescents and adults. European Journal of Clinical Nutrition, 57, 842-853. 
Kidd, P. S., \& Parshall, M. B. (2000). Getting the focus and the group: Enhancing analytical rigor in focus group research. Qualitative Health Research, 10, 293-308.

Kline, S. (2005). Countering children's sedentary lifestyles: An evaluative study of a media-risk education approach. Childhood, 12, 239-258.

Madarasová Gecková, A., Veselská, Z., \& Kollárová, J. (Eds.). (2011). HBSC - Slovensko 2009/2010. Sociálne determinanty zdravia školákov [HBSC - Slovakia 2009/2010. Social determinants of schoolchildren's health]. Košice, Slovakia: Equilibria.

May, C., Chai, L. K., \& Burrows, T. (2017). Parent, partner, co-parent or partnership? The need for clarity as family systems thinking takes hold in the quest to motivate behavioural change. Children, 4, 29.

Morris, A., \& Katzman, D. (2003). The impact of the media on eating disorders in children and adolescents. Paediatrics \& Child Health, 8, 287-289.

Naaeni, M. M., Jafari, S., Fouladgar, M., Heidari, K., Farajzadegan, Z., Fakhri, M., ... Omidi, R. (2014). Nutritional knowledge, practice, and dietary habits among school children and adolescents. International Journal of Preventive Medicine, 5, 171-178.

Pitt, M. P., Berger, J. N., \& Sheehan, K. M. (2016). Compliance of parenting magazines advertisements with American Academy of Pediatrics recommendations. Children, 3, 23.

Ramos, M., \& Stein, L. M. (2000). Development children's eating behavior. Jornal de Pediatria, 76(Suppl. 3), S229-S237.

Reisigg, C. J., Strain, E. C., \& Griffiths, R. R. (2009). Caffeinated energy drinks - a growing problem. Drug and Alcohol Dependence, 99, 1-10.

Schulze, M. B., Manson, J. E., Ludwig, D. S., Colditz, G. A., Stampfer, M. J., Willett, W. C., \& Hu, F. B. (2004). Sugarsweetened beverages, weight gain, and incidence of type 2 diabetes in young and middle-aged women. Journal of the American Medical Association, 292, 927-934.
Simovska, V. (2007). The changing meanings of participation in school-based health education and health promotion: The participants voices. Health Education Research, 22, 864-878.

Solberg, A. (1996). The challenge in child research: From 'being' to 'doing'. In J. Brannen \& M. O’Brien (Eds.), Children in families. Research and policy (pp. 53-65). London, United Kingdom: Falmer Press.

Spencer, G. (2013). Young people's perspectives on health: Empowerment, or risk? Health Education, 113, 115-131.

Švařiček, R., Šed’ová, K., Janík, T., Kaščák, O., Miková, M., Nedbálková, K., ... Zounek, J. (2007). Kvalitativní výzkum v pedagogických vědách: pravidla hry [Qualitative research in pedagogical sciences: The rules of game]. Prague, Czech Republic: Portál.

Tong, A., Sainsbury, P., \& Craig, J. (2007). Consolidated criteria for reporting qualitative research (COREQ): A 32-item checklist for interviews and focus groups. International Journal for Quality in Health Care, 19, 349-357.

U.S. Department of Health and Human Services, Centers for Disease Control and Prevention. (2013). Make a difference at your school: $C D C$ resources can help you implement strategies to prevent obesity among children and adolescents. Retrieved from https://www.cdc.gov/healthyyouth/keystrategies/pdf/make-a-difference.pdf

Vartanian, L. R., Schwartz, M. B., \& Brownell, K. D. (2007). Effects of soft drink consumption on nutrition and health: A systematic review and meta-analysis. American Journal of Public Health, 97, 667-675.

Word Health Organization. (2006). Food and nutrition policy for schools: A tool for the development of school nutrition programmes in the European region. Retrieved from http:// www.euro.who.int/_data/assets/pdf_file/0019/152218/ E89501.pdf?ua=1

Wilson, J. M., Tripp, D. A., \& Boland, F. J. (2005). The relative contributions of subjective and objective measures of body shape and size to body image and disordered eating in women. Body Image, 2, 233-247. 